\title{
Hemodynamic monitoring and management in patients undergoing high risk surgery: a survey among North American and European anesthesiologists
}

\author{
Maxime Cannesson ${ }^{1 *}$, Gunther Pestel ${ }^{2}$, Cameron Ricks ${ }^{1}$, Andreas Hoeft ${ }^{3}$ and Azriel Perel ${ }^{4}$
}

\begin{abstract}
Introduction: Several studies have demonstrated that perioperative hemodynamic optimization has the ability to improve postoperative outcome in high-risk surgical patients. All of these studies aimed at optimizing cardiac output and/or oxygen delivery in the perioperative period. We conducted a survey with the American Society of Anesthesiologists (ASA) and the European Society of Anaesthesiology (ESA) to assess current hemodynamic management practices in patients undergoing high-risk surgery in Europe and in the United States.

Methods: A survey including 33 specific questions was emailed to 2,500 randomly selected active members of the ASA and to active ESA members.

Results: Overall, 368 questionnaires were completed, 57.1\% from ASA and 42.9\% from ESA members. Cardiac output is monitored by only $34 \%$ of ASA and ESA respondents $(P=0.49)$ while central venous pressure is monitored by $73 \%$ of ASA respondents and $84 \%$ of ESA respondents $(P<0.01)$. Specifically, the pulmonary artery catheter is being used much more frequently in the US than in Europe in the setup of high-risk surgery (85.1\% vs. $55.3 \%$ respectively, $P<0.001$ ). Clinical experience, blood pressure, central venous pressure, and urine output are the most widely indicators of volume expansion. Finally, $86.5 \%$ of ASA respondents and $98.1 \%$ of ESA respondents believe that their current hemodynamic management could be improved.
\end{abstract}

Conclusions: In conclusion, these results point to a considerable gap between the accumulating evidence about the benefits of perioperative hemodynamic optimization and the available technologies that may facilitate its clinical implementation, and clinical practices in both Europe and the United States.

\section{Introduction}

Mortality and morbidity related to anesthesiology have significantly decreased during the last decade, mainly due to improvements in patients' safety in general, as well as better risk stratification and better management. However, complications following major surgery are still a leading cause of perioperative morbidity and mortality $[1,2]$. High-risk surgical patients represent only about $10 \%$ of the overall anesthesiology procedures performed each year, and yet these patients account for over $80 \%$

\footnotetext{
* Correspondence: maxime_cannesson@hotmail.com

'Department of Anesthesiology and Perioperative Care, School of Medicine,

University of California, Irvine, 101 S City Drive, Orange, CA 92868, USA

Full list of author information is available at the end of the article
}

of perioperative deaths [3]. This represents a substantial global public-health concern since it is estimated that 234 million major surgical procedures are performed worldwide each year including 40 millions in the US alone [4].

Several studies have demonstrated that perioperative hemodynamic optimization has the ability to improve postoperative outcome in high-risk surgical patients [5-7]. Specifically, hemodynamic optimization in patients undergoing high-risk surgery has been shown to decrease the incidence of postoperative complications, to decrease length of stay in the intensive care unit and in the hospital, to decrease the overall cost of surgery [6], and to possibly improve long-term survival [8].

\section{C) Biomed Central}


More than a decade ago it was already claimed that it may be considered unethical not to use goal-directed perioperative therapy once patient identification and the methods to be used in treating them are refined [9]. And yet, the principles of perioperative optimization are not applied uniformly, if at all, and there is a great variability in their adoption into clinical practice.

Part of the observed non-uniformity in the clinical application of perioperative optimization may be due to the prevalent different practices in hemodynamic monitoring with regard mainly to the measurement of cardiac output (CO). The most frequent parameters that have been used for perioperative optimization are cardiac output (CO) and/or oxygen delivery (DO2). Although the proclaimed gold standard for cardiac output measurement is still intermittent thermodilution by the pulmonary artery catheter (PAC), the use of this device has dramatically decreased in surgical patients over the past 15 years [10]. This decrease is mostly related to the fact that the PAC is highly invasive and has several associated risks [10]. One should consider, however, that the apparent decline in the use of PACs is due to both a shift in philosophy and its replacement by new technologies [11].

The aim of the present study is, therefore, to assess and report current hemodynamic management practices in patients undergoing high-risk surgery in Europe and in the United States using a self reported internet survey. The results from this study will help to determine the potential need for future educational endeavors and practice guidelines regarding hemodynamic monitoring and management in patients undergoing high-risk surgery.

\section{Materials and methods}

A survey of 33 questions was developed to assess the current trend in hemodynamic management and monitoring for high-risk surgery patients. Twelve questions were related to the respondents' demographic data and practice.

The Institutional Review Board at the University of California Irvine approved the study. An invitation to participate in the survey was emailed through the American Society of Anesthesiology (ASA) e-newsletter to 2,500 randomly selected active members of the ASA, representing approximately $10 \%$ of the active membership. At the same time, an email was sent through the European Society of Anaesthesiology (ESA) office to active ESA members with a link to the survey and a link to the survey was posted on the European Society of Anaesthesiology website. Below is the invitation that was sent to ASA and ESA members:

Dear ASA/ESA member,
We are inviting you to participate in a research project regarding our current practices of hemodynamic monitoring and management in patients undergoing high-risk surgery. Information regarding your practice, experiences, philosophies, and training will be used to assess the potential need for future educational endeavors and practice guidelines.

The way in which patients are monitored and their outcomes are optimized is rapidly evolving and improving. However, setting a standard of care with the use of new methods has yet to be achieved. In particular, hemodynamic monitors and indices available in high-risk surgery patients have markedly evolved. Currently, even if pulmonary artery catheterization remains the gold standard for hemodynamic monitoring in high-risk patients, its use has dramatically declined (63\%) in the last 15 years. While this decline is largely due to the fact that the device is highly invasive and has several associated risks, it may also be due to changes in philosophy or implementation of new technologies. This questionnaire has been approved by the ASA/ESA for distribution to its members. At the end of this email there is a link to a 33-question Survey Monkey questionnaire, which should take about 10 minutes to complete. Participation in this questionnaire is completely voluntary and anonymous. We hope that you will take the time to fill out this questionnaire and help us to uncover the potential need for standardizing hemodynamic practices in high-risk surgical patients.

Resident, affiliate, honorary, life, and retired members were excluded. A covering letter explained that the data collected would be anonymous and be non-attributable. Participants accessed a Web site linked to a secure database (Survey Monkey, Palo Alto, CA, USA). The survey was opened from 1 October 2010 to 31 December 2011. To maximize response rate, we sent two sequential emails to the participants during the study period. 


\section{Survey questions}

In the survey, high risk surgery patients were defined and presented according to the definition presented below:

For the following questionnaire, we will define high risk surgery patients as patients aged 18 years or older presenting for major surgery expected to last more than 1.5 hours and having at least two of the following criteria:

1. Cardiac or respiratory illness resulting in functional limitation

2. Extensive surgery planned for carcinoma involving bowel anastomosis

3. Predictable acute massive blood loss $(>2.5$ liters)

4. Aged over 70 years with functional limitation of one or more organ systems

5. Septicemia (positive blood cultures or septic focus)

6. Respiratory failure $(\mathrm{PaO} 2<8 \mathrm{kPa}$ on FiO2 > 0.4 , that is, $\mathrm{PaO} 2$ :FiO2 ratio $<20 \mathrm{kPa}$ or ventilation $>48$ hours)

7. Acute abdominal catastrophe (for example, pancreatitis, perforated viscous, gastro-intestinal bleed)

8. Acute renal failure (urea $>20 \mathrm{mmol} \mathrm{l}^{-1}$, creatinine $>260 \mu \mathrm{mol} \mathrm{l} \mathrm{l}^{-1}$ )

9. Surgery for abdominal aortic aneurysm

10. Disseminated malignancy

This definition has been used in previously published studies on the topic both in the US and in Europe $[5,12,13]$. The full questionnaires sent to ASA and ESA members are presented in Appendix 1 and 2 respectively.

\section{Statistical analysis}

Categorical data are expressed as frequency. Data were analyzed according to the number of responses we obtain for each given question. Categorical items were analyzed by frequency distribution and $\chi 2$ analysis. In all cases, two-tailed $P$-values of 0.05 or less were considered evidence of differences not attributable to chance. All analyses were performed using SPSS 11.0 (SPSS Inc., Chicago, IL, USA).

\section{Results}

\section{Respondents' description}

We received 217 responses from ESA members and 273 responses from ASA members. Total completed questionnaires were 158 (72.8\%) for ESA members and 210 (76.9\%) for ASA members. Overall, 368 questionnaires were completed, including $57.1 \%$ from ASA members and $42.9 \%$ from ASA members.

\section{ASA respondents' descriptions}

ASA respondents are working mostly (48\%) in private practice with lesser numbers working in general hospitals $(24.2 \%)$ and in university hospitals (25.4\%). About half $(51.8 \%)$ of them take care of high risk surgery patients 1 to 5 times a week and about a third (35.1\%) of them do it 6 to 10 times a week, with only $13.8 \%$ of them taking care of cardiac surgery patients. Half of them had further training, including a fellowship in cardiac anesthesia (48.5\%) and in critical care (25.8\%). About a third (33.8\%) finished their training after 2000 and $6.2 \%$ before 1980 . Only $31.6 \%$ of the ASA respondents manage high-risk surgical patients in the intensive care unit.

\section{ESA respondents description}

ESA respondents are working mostly (54.0\%) in university hospitals, with lesser numbers working in general hospitals $(37.6 \%)$ and in private practice $(5.0 \%)$. The majority, (72.8\%), take care of high-risk surgery patients 1 to 5 times a week and $18.3 \%$ do it 6 to 10 times a week, with $10.3 \%$ taking care of cardiac surgery patients. One third (31.2\%) of ESA member respondents had further training, including a fellowship in critical care $(58.3 \%)$ or in cardiac anesthesia $(33.3 \%)$. About half (45.8\%) finished their training after 2000 and $7.1 \%$ before 1980 . The majority (79.7\%) of ESA respondents manage high-risk surgical patients in the intensive care unit.

Although more ASA respondents work in private practice than ESA respondents $(48.0 \%$ vs. $5.0 \%$; $P<$ $0.001)$, they manage high-risk surgery patients more often than ESA respondents (6 to 10 times/week in $35.1 \%$ of ASA respondents vs. $18.7 \%$ of ESA respondents; $P<0.001)$. Interestingly, $18.6 \%$ of ESA respondents work in hospitals of $>1,000$ beds (vs. 5.7\% ASA respondents; $P<0.001)$; yet intensive care units with $>$ 40 beds are more frequent in the US (37.9\% ASA vs. $17.8 \%$ ESA; $P<0.001)$. For ESA respondents, critical care and anesthesiology belong to the same group; this is different for ASA respondents (Figure 1). ESA respondents seem to be younger: $46.2 \%$ of them finished training after 2000 (vs. 33.8\% of ASA respondents; $P<$ 0.001). The term "fellowship" seems unfamiliar to ESA respondents: $24.1 \%$ of them answer "not applicable" (vs. $0 \%$ of ASA respondents).

\section{Hemodynamic monitoring and management practices}

Hemodynamic monitoring practices seem to differ considerably between Europe and the USA (Table 1), with more Europeans having written protocols concerning hemodynamic management in high-risk surgical patients 


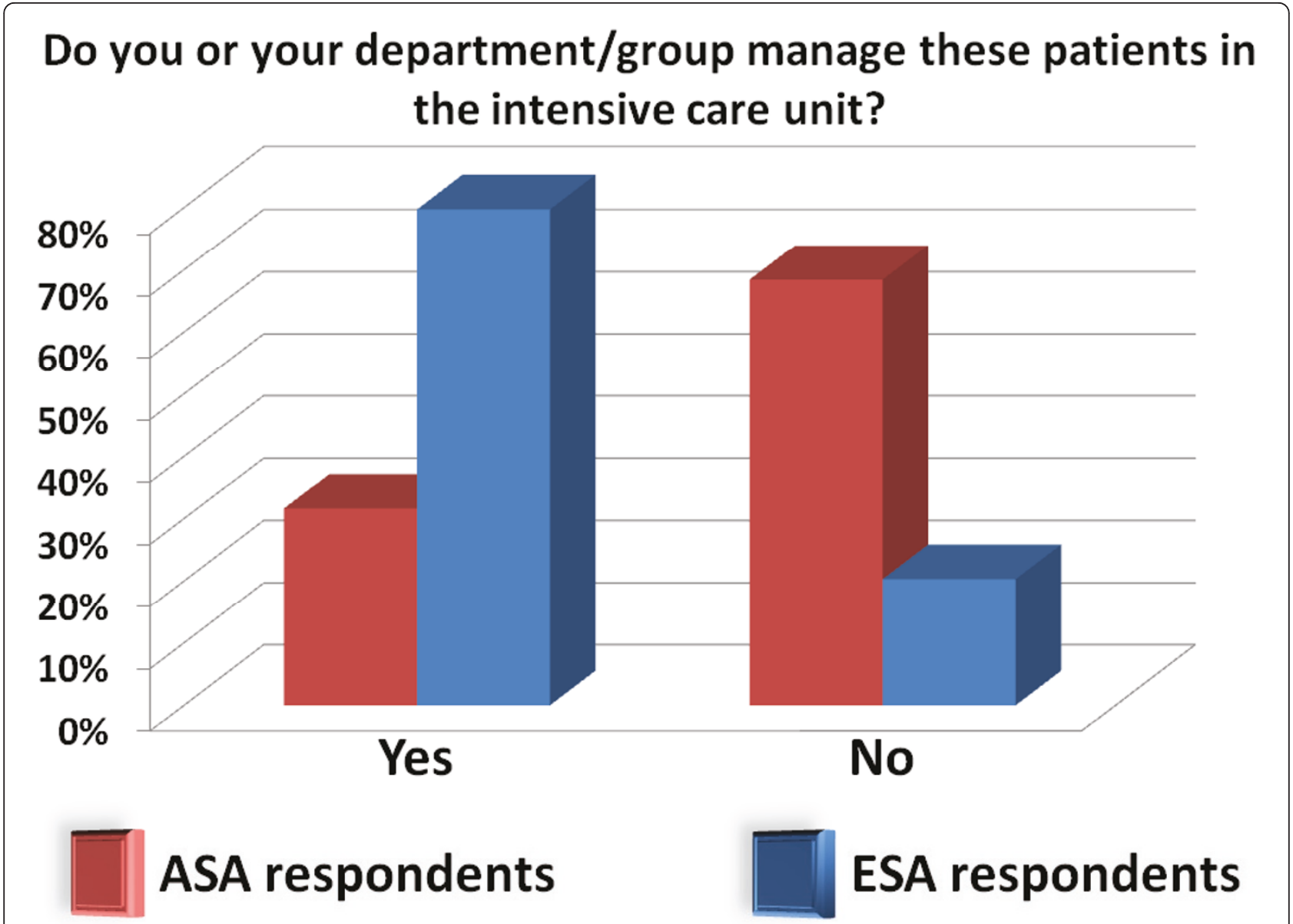

Figure 1 Do you or your department/group manage these patients in the intensive care unit?

than Americans $(30.4 \%$ and $5.4 \%$, respectively, $P<$ 0.001) (Figure 2).

Invasive blood pressure and central venous pressure monitoring

While invasive arterial pressure is monitored and used for hemodynamic optimization by more than $90 \%$ of both ASA and ESA respondents, there seems to exist significant heterogeneity in the way $\mathrm{CVP}$ and $\mathrm{CO}$ are being monitored and used (Figure 3). Interestingly, CVP is monitored by $84 \%$ of ESA respondents and by $73 \%$ of ASA respondents $(P<0.05)$. In contrast, ESA or ASA respondents rarely optimize CVP while most of them optimize arterial pressure.

\section{Cardiac output monitoring}

Although CO is being monitored by only about $34 \%$ of both ASA and ESA respondents $(P=0.491)$, we observed significant differences regarding the techniques used for $\mathrm{CO}$ monitoring by ASA and ESA respondents (Figure 4). Specifically, the PAC is being used much more frequently in the US than in Europe in the setup of high-risk surgery $(85.1 \%$ vs. $55.3 \%$ respectively, $P<$
0.001). On the other hand, the PiCCO monitor is used in this setup by $44.0 \%$ of ESA respondents and by only $1.1 \%$ of ASA respondents $(P<0.001)$. When respondents reported that they do not monitor $\mathrm{CO}$, the main reason given by both groups was that they monitor dynamic parameters of fluid responsiveness as surrogates for $\mathrm{CO}$ monitoring (Table 2). Additionally, technologies for $\mathrm{CO}$ monitoring are considered by the nonusers of both groups to be too invasive (Table 2). Interestingly, although $\mathrm{CO}$ is being measured by only a third of ASA and ESA respondents, nearly all respondents agree that oxygen delivery is of major importance for patients undergoing high-risk surgery, with more than $90 \%$ exhibiting the knowledge that $\mathrm{CO}$ is a major determinant of oxygen delivery.

Dynamic parameters of fluid responsiveness

Parameters considered by both ASA and ESA respondents as indicators for volume expansion are shown in Table 3. Clinical experience, blood pressure, CVP, and urine output are the most widely seen indicators of volume expansion. ESA respondents are more likely to 
Table 1 Hemodynamic monitoring used for the management of high-risk surgery patients?.

\begin{tabular}{lcc}
\hline & $\begin{array}{c}\text { ASA } \\
\text { respondents } \\
(\boldsymbol{n}=\mathbf{2 3 7})\end{array}$ & $\begin{array}{c}\text { ESA } \\
\text { respondents } \\
(\boldsymbol{n}=\mathbf{1 9 5})\end{array}$ \\
\hline Answer options & $\begin{array}{c}\text { Response } \\
\text { percent }\end{array}$ & $\begin{array}{c}\text { Response } \\
\text { percent }\end{array}$ \\
\hline Invasive arterial pressure & $95.4 \%$ & $89.7 \%$ \\
Central venous pressure & $72.6 \%$ & $83.6 \%$ \\
Non-invasive arterial pressure & $51.9 \%$ & $53.8 \%$ \\
Cardiac output & $35.4 \%$ & $34.9 \%$ \\
Pulmonary capillary wedge & $30.8 \%$ & $14.4 \%$ \\
pressure & & \\
Transesophageal & $28.3 \%$ & $19.0 \%$ \\
echocardiography & & \\
Systolic pressure variation & $20.3 \%$ & $23.6 \%$ \\
Plethysmographic waveform & $17.3 \%$ & $17.9 \%$ \\
variation & & \\
Pulse pressure variation & $15.2 \%$ & $25.6 \%$ \\
Mixed venous saturation (ScvO2) & $14.3 \%$ & $15.9 \%$ \\
Central venous saturation (SvO2) & $12.7 \%$ & $33.3 \%$ \\
Oxygen delivery (DO2) & $6.3 \%$ & $14.4 \%$ \\
Stroke volume variation & $6.3 \%$ & $21.5 \%$ \\
Near infrared spectroscopy & $4.6 \%$ & $5.1 \%$ \\
Global end diastolic volume & $2.1 \%$ & $8.2 \%$ \\
\hline ASA, American society of aneshesogy & & \\
\hline
\end{tabular}

ASA, American society of anesthesiology respondents; ESA, European society of anaesthesiology respondents.

use dynamic parameters of fluid responsiveness based on arterial pressure analysis than ASA respondents. The way ASA and ESA respondents assess the hemodynamic effects of a volume expansion is shown in Table 4. Parameters considered as the best predictors of fluid responsiveness by ASA and ESA respondents are shown in Table 5.

Respiratory variations in the plethysmographic waveform are being used by $25 \%$ of ASA and ESA respondents. Respiratory variations in arterial pressure are eyeballed by $90.3 \%$ of ASA respondents compared with $68.0 \%$ of ESA respondents $(P<0.001)$, manually calculated by $9.7 \%$ of ASA respondents and by $20.6 \%$ of ESA respondents, and monitored using specific software by $5.1 \%$ of ASA respondents versus $22.9 \%$ of ESA respondents $(P<0.001)$. These parameters are optimized more than $50 \%$ of the time by $31.2 \%$ of ASA respondents and by $28.4 \%$ of ESA respondents $(P<0.298)$.

A significant difference was observed regarding the type of fluid used by ASA and ESA respondents. Crystalloid is the first line therapy used by ASA respondents while ESA respondents chose starches (Figure 5).

To the question: "Do you believe that your current hemodynamic management could be improved?" $86.5 \%$ of ASA respondents and $98.1 \%$ of ESA respondents $(P<$ 0.001) answered "Yes".

\section{Discussion}

The main finding of this international survey is that despite evidence showing that $\mathrm{CO}$ optimization during high risk surgery has the potential to improve postoperative patient outcome, and despite the fact that nearly all respondents agreed that oxygen delivery is of major importance for patients undergoing high-risk surgery, only $34 \%$ of anesthesiologists in Europe and in the US monitor $\mathrm{CO}$ in this setting. More importantly, even those who monitor $\mathrm{CO}$ rarely use its value for perioperative optimization as recommended in recent articles $[6,8]$. Interestingly, $86.5 \%$ of ASA respondents and 98.1\% of ASA respondents believe that their current hemodynamic management could be improved. The other findings of this survey point out significant differences in the choice and interpretation of monitoring techniques between American and European anesthesiologists

The role of $\mathrm{CO}$ monitoring and optimization in improving outcome in high-risk surgery is being repeatedly demonstrated in recent years $[6,7,14]$. Yet, as our study clearly demonstrates, the adoption of this therapeutic approach is far from being universal. This is reflected by the fact that most of the responding centers do not have clear recommendations or guidelines for hemodynamic management of high-risk surgery patients (Figure 1). One of the main reasons for the apparent reluctance to monitor $\mathrm{CO}$ is the belief that in and by itself $\mathrm{CO}$ is not an important parameter, and that the clinicians may be better off by using other parameters, like dynamic predictors of fluid responsiveness, as surrogates of CO (Table 2) [15]. However, only $24.2 \%$ of ASA respondents and $14.1 \%$ of ESA respondents think that $\mathrm{CO}$ monitoring does not provide any additional clinically relevant information for the management of highrisk surgery patients. A much larger portion of the respondents, $48.4 \%$ of the ASA and $26.8 \%$ of the ESA, do not monitor $\mathrm{CO}$ because they feel that available solutions are too invasive. Another explanation for the relative scarcity of $\mathrm{CO}$ monitoring, which was not explored in our study, is the uncertainty of anesthesiologists about the value of perioperative optimization in general, in view of the studies that have shown that fluid restriction might be beneficial for high-risk surgical patients $[16,17]$.

More than $50 \%$ of respondents stated that they are using dynamic predictors of fluid responsiveness as a surrogate for $\mathrm{CO}$ monitoring. The ability of dynamic parameters to predict fluid responsiveness accurately has been extensively demonstrated [18-21]. Indeed, functional hemodynamic parameters may be helpful in identifying fluid responders prior to hemodynamic optimization, and, more importantly, identify those patients 


\section{Does your institution or group have a written protocol, care guide, or statement concerning hemodynamic management in this setting?}

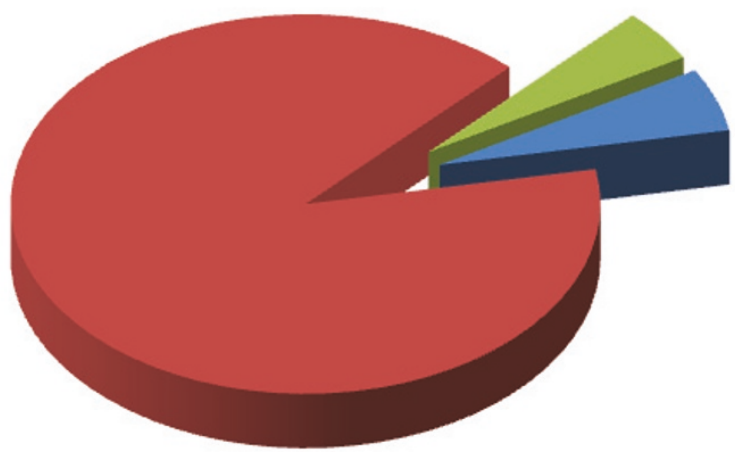

ASA Respondents
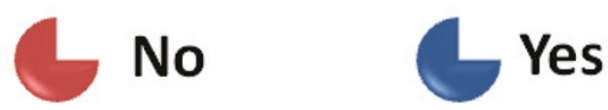

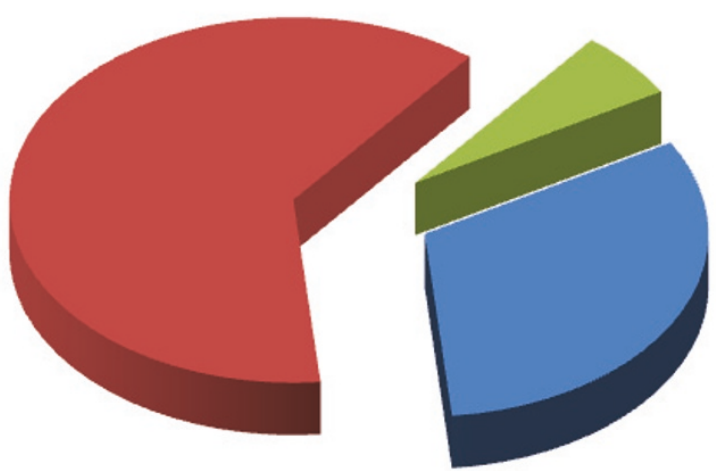

ESA Respondents

\section{Unsure or don't know}

Figure 2 Incidence of institutional guidelines concerning hemodynamic management in this setting?

who are not likely to respond to fluids and, thereby, prevent detrimental fluid overload. However, studies showing an impact of hemodynamic management based on these parameters on patients' outcome are still lacking and so far we have no strong evidence supporting this hypothesis [22]. Moreover, it has been shown recently that about $60 \%$ of patients present at least one limitation to the use of dynamic parameters in the operating room [23]. Finally, about $90 \%$ of ASA respondents and $70 \%$ of ESA respondents only eyeball these variations precluding any strong clinical application.

Our results show that there are significant differences between American and European anesthesiologists in the practice of hemodynamic monitoring. It seems that most clinicians in the US still associate $\mathrm{CO}$ monitoring with the use of the Swan-Ganz catheter (Figure 4) while other less invasive monitors are not widely known or used. For example, the transpulmonary thermodilution method that is applied in the $\mathrm{PiCCO}^{\circledR}$ and is used by $44.0 \%$ of the ESA respondents, seems to be virtually unknown to most clinicians in the US. This could be explained by the fact that this technology requires a femoral arterial line, which is not the standard of care in the US [24]. Another explanation is that technologies seem to spread most in the countries and regions where they are developed and manufactured, due most probably to the involvement of local opinion leaders in the development and validation phases, as well as in the marketing efforts, but this has to be demonstrated. The observed differences between European and US practices in terms of technology and hemodynamic knowhow may also stem from the fact that anesthesiologists in Europe are more likely to be ICU and because they manage patients in the ICU more frequently than their American colleagues (Figure 2). We postulate that this may also explain our finding that the number of ESA respondents who use the mixed venous oxygen saturation $(\mathrm{SvO} 2)$ and/or central venous oxygen saturation ( $\mathrm{ScVO} 2)$ as surrogates for $\mathrm{CO}$ monitoring is double than that of ASA respondents since goal directed therapy based on $\mathrm{ScvO} 2$ optimization has been validated in septic patients in the intensive care unit [25].

An intriguing finding of our study relates to the monitoring of central venous pressure (CVP) which is still 

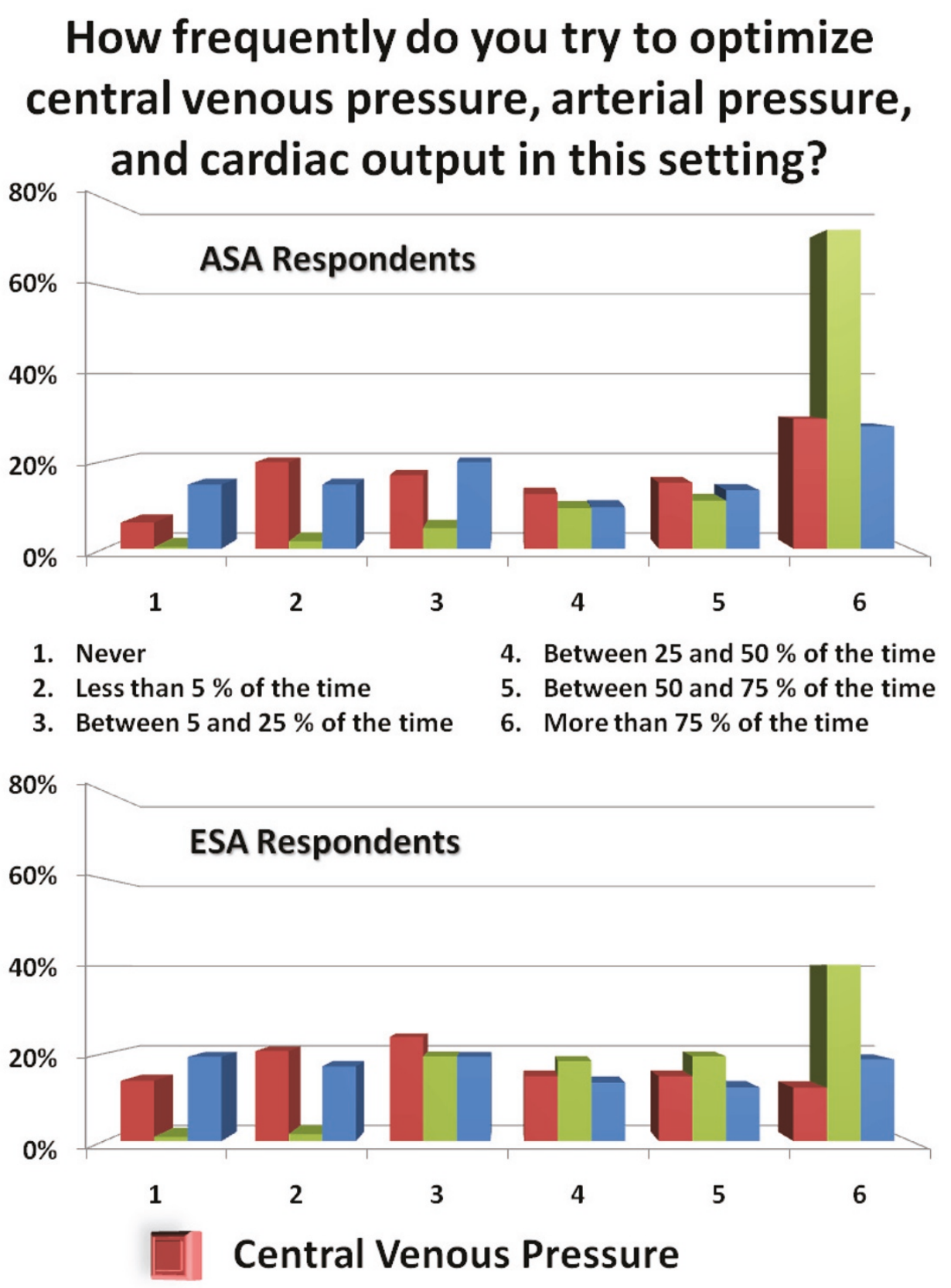

\section{Arterial Pressure}

\section{Cardiac Output}

Figure 3 How frequently do you try to optimize central venous pressure, arterial pressure, and cardiac output in this setting?

frequently monitored on both continents (Table 1) despite consistent evidence that filling pressures are unreliable in predicting fluid responsiveness [26,27] and that they have numerous limitations [28]. Since most clinicians who monitor CVP admit that they do not try to optimize it (Figure 3), it is unclear how CVP is integrated into the physicians' clinical decision-making process. In 2007, in an editorial published in Critical Care 


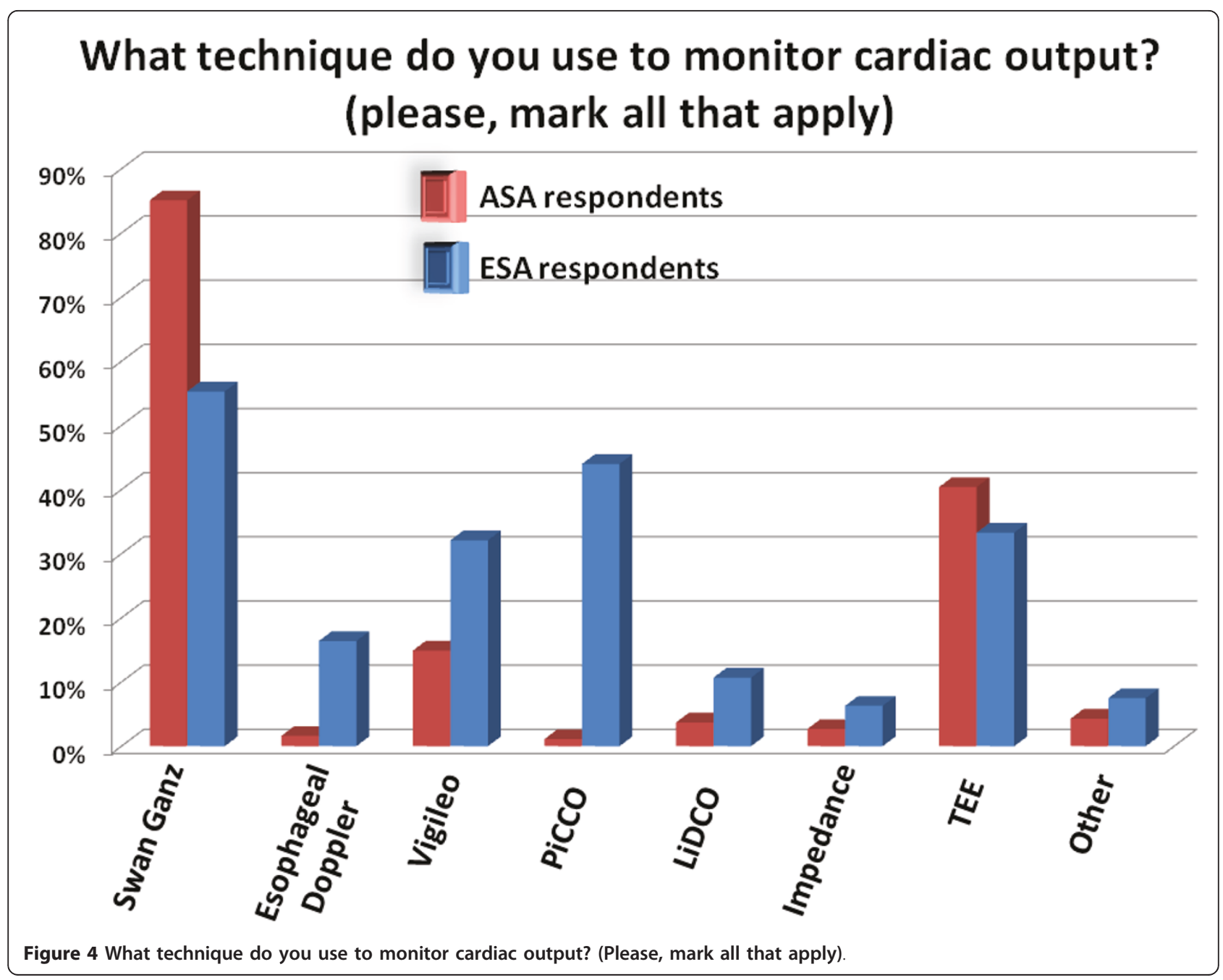

Medicine, Dr. Parker claimed that better methods for determining cardiac preload and cardiac performance are badly needed to guide the clinician in the management of our critically ill patients, but until these methods become more widely available we are left with pressure measurements and clinical judgment [29]. This seems to still be the case for many anesthesiologists, even though new technologies and devices, including those that monitor dynamic predictors of fluid responsiveness, are indeed widely available.

\section{Study limitations}

The accuracy of our survey can be impacted by ascertainment and non response bias. Our response rate was relatively small, and the clinicians who responded may not be representative, which could impact the external

Table 2 Main reasons for not monitoring cardiac output?

\begin{tabular}{|c|c|c|}
\hline & $\begin{array}{l}\text { ASA Respondents } \\
\quad(n=157)\end{array}$ & $\begin{array}{l}\text { ESA Respondents } \\
\quad(n=142)\end{array}$ \\
\hline Answer Options & Response Percent & Response Percent \\
\hline $\begin{array}{l}\text { I use dynamic parameters of fluid responsiveness (Pulse Pressure Variations, Systolic Pressure Variations, } \\
\text { Plethysmographic Waveform Variations) as surrogates for cardiac output monitoring }\end{array}$ & $54.1 \%$ & $60.6 \%$ \\
\hline Available cardiac output monitoring solutions are too invasive & $48.4 \%$ & $26.8 \%$ \\
\hline Cardiac output monitoring does not provide any additional clinically relevant information in this setting & $24.2 \%$ & $14.1 \%$ \\
\hline I use SvO2 and/or ScVO2 as surrogates for cardiac output monitoring & $13.4 \%$ & $26.1 \%$ \\
\hline Available cardiac output monitoring solutions are unreliable & $8.3 \%$ & $15.5 \%$ \\
\hline
\end{tabular}

ASA, American society of anesthesiology respondents; ESA, European society of anaesthesiology respondents. 
Table 3 What are your indicators for volume expansion in this setting (diagnostic tools)?

\begin{tabular}{lcc}
\hline & $\begin{array}{c}\text { ASA } \\
\text { Respondents } \\
(\boldsymbol{n}=\mathbf{2 0 9})\end{array}$ & $\begin{array}{c}\text { ESA } \\
\text { Respondents } \\
(\boldsymbol{n}=\mathbf{1 6 5})\end{array}$ \\
\hline Answer Options & $\begin{array}{c}\text { Response } \\
\text { Percent }\end{array}$ & $\begin{array}{c}\text { Response } \\
\text { Percent }\end{array}$ \\
\hline Blood pressure & $88.5 \%$ & $77.6 \%$ \\
Urine output & $83.3 \%$ & $77.0 \%$ \\
Clinical experience & $77.5 \%$ & $64.8 \%$ \\
Central venous pressure & $70.8 \%$ & $64.2 \%$ \\
Cardiac output & $49.3 \%$ & $53.3 \%$ \\
Pulse Pressure Variation or Systolic & $45.0 \%$ & $55.8 \%$ \\
Pressure Variation & & \\
Transesophageal echocardiography & $43.5 \%$ & $28.5 \%$ \\
Pulmonary capillary wedge pressure & $38.8 \%$ & $24.2 \%$ \\
Plethysmographic Waveform Variation & $25.4 \%$ & $25.5 \%$ \\
Stroke Volume Variation & $19.1 \%$ & $36.4 \%$ \\
Mixed venous saturation (ScvO2) & $18.7 \%$ & $21.8 \%$ \\
Global end diastolic volume & $10.5 \%$ & $17.0 \%$ \\
Central venous saturation (SvO2) & $10.0 \%$ & $34.5 \%$ \\
\hline ASA A &
\end{tabular}

ASA, American society of anesthesiology respondents; ESA, European society of anaesthesiology respondents.

validity of these results. This is a common limitation to online or email surveys, and has been well documented $[30,31]$. One way of bypassing this limitation is to use a professional mailing list in order to reach a specific target population [31] as we did in the present study. However, it is interesting to observe the concordance between ESA and ASA respondents' answers and our results seem in accordance with commonly observed practice in Europe and in the US. Moreover, our goal

Table 4 How do you routinely assess the hemodynamic effects of volume expansion?

\begin{tabular}{lcc}
\hline & $\begin{array}{c}\text { ASA } \\
\text { respondents } \\
(\boldsymbol{n}=\mathbf{2 0 3})\end{array}$ & $\begin{array}{c}\text { ESA } \\
\text { respondents }(\boldsymbol{n} \\
\mathbf{=}\end{array}$ \\
\hline Answ)
\end{tabular}

ASA, American society of anesthesiology respondents; ESA, European society of anaesthesiology respondents.
Table 5 In your opinion, what best predicts an increase in cardiac output following volume expansion?

\begin{tabular}{lcc}
\hline & $\begin{array}{c}\text { ASA } \\
\text { Respondents } \\
(\boldsymbol{n}=\mathbf{1 9 0})\end{array}$ & $\begin{array}{c}\text { ESA } \\
\text { Respondents } \\
(\boldsymbol{n}=\mathbf{1 5 8})\end{array}$ \\
\hline Answer options & $\begin{array}{c}\text { Response } \\
\text { percent }\end{array}$ & $\begin{array}{c}\text { Response } \\
\text { percent }\end{array}$ \\
\hline Transesophageal echocardiography & $26.8 \%$ & $17.7 \%$ \\
Cardiac output & $21.1 \%$ & $20.9 \%$ \\
Blood pressure & $14.2 \%$ & $5.7 \%$ \\
Pulse pressure variation or systolic & $12.1 \%$ & $12.0 \%$ \\
pressure variation & $7.9 \%$ & $5.7 \%$ \\
Mixed venous saturation (ScvO2) & $5.8 \%$ & $21.5 \%$ \\
Stroke volume variation & $5.3 \%$ & $3.2 \%$ \\
Clinical experience & $2.1 \%$ & $3.2 \%$ \\
Pulmonary capillary wedge pressure & $2.1 \%$ & $1.9 \%$ \\
Central venous saturation (SvO2) & $1.1 \%$ & $3.2 \%$ \\
Central venous pressure & $1.1 \%$ & $3.8 \%$ \\
Global end diastolic volume & $0.5 \%$ & $1.3 \%$ \\
Plethysmographic waveform variations & & \\
\hline ASA, Am & &
\end{tabular}

ASA, American society of anesthesiology respondents; ESA, European society of anesthesiology respondents.

was not to develop recommendations based on the extent of existing practice, but rather to establish a baseline against which consensus proposals would be developed. We also believe these results can be used in the future to assess the effects of guidelines/recommendations on clinical practice and hemodynamic monitoring/ management in patients undergoing high risk surgery.

\section{Conclusions}

In conclusion, these results point to a considerable gap between the accumulating evidence about the benefits of perioperative hemodynamic optimization and the available technologies that may facilitate its clinical

\section{What is your first choice solution for volume expansion?}

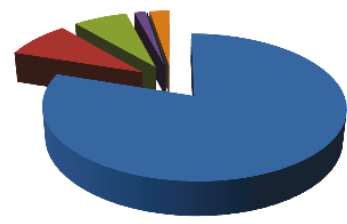

ASA Respondents

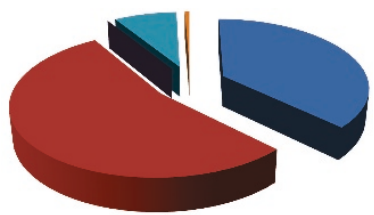

ESA Respondents

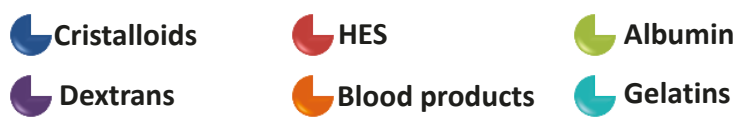

Figure 5 What is your first choice solution for volume expansion? 
implementation, and clinical practices in both Europe and the US. In addition, clinical practice may be heavily influenced by local factors that may not be justified by basic physiological considerations and the recently published body of evidence.

We postulate that we may be missing an enormous opportunity for better hemodynamic understanding, management and standardization. Clinicians may have adequate physiological knowledge but clinical application needs to be improved. Better communication, exchange of ideas and exposure to new technologies may decrease the observed differences between American and European anesthesiologists. On the local level, practical bedside teaching, simulation, and well-defined workshops may help to promote the use of appropriate hemodynamic management and goal directed therapy concepts. Recent and most important advances in anesthesia and critical care have been provided by "check list" implementations [32,33]. Standardization of practice and making sure that adequate therapies are delivered effectively may be the next step for hemodynamic management of patients undergoing high-risk surgery.

\section{Key messages}

- Our results point to a considerable gap between the accumulating evidence about the benefits of perioperative hemodynamic optimization and the available technologies that may facilitate its clinical implementation, and clinical practices in both Europe and the US.

- Clinical practice may be heavily influenced by local factors that may not be justified by basic physiological considerations and the recently published body of evidence. We may thus be missing an enormous opportunity for better hemodynamic understanding, management and standardization.

- This lack of application of goal directed therapy concepts is not related to a lack of knowledge.

- The results of this email survey with a low response rate seems to emphasize the need for large clinical studies in order to demonstrate the clinical utility of intraoperative goal directed therapy during high risk surgery.

\section{Additional material}

Additional file 1: Appendix 1. Full questionnaire sent to American Society of Anesthesiologists members. A pdf. file with the full length questionnaire.

Additional file 2: Appendix 1. Full questionnaire sent to the European Society of Anaesthesiology members. A pdf. file with the full length questionnaire.

\section{Abbreviations}

ASA: American Society of Anesthesiologists; CO: cardiac output; CVP: central venous pressure; DO2: oxygen delivery; ESA: European Society of Anaesthesiology; PAC: pulmonary artery catheter

\section{Acknowledgements}

The authors wish to thank Dr. Celeste Kirshner and Sandrine Damster for their help and assistance in conducting this survey. Financial support: None

IRB: This study has been approved by the IRB of the University of California Irvine. This committee can be reached at irb@rgs.uci.edu

\section{Author details}

'Department of Anesthesiology and Perioperative Care, School of Medicine, University of California, Irvine, 101 S City Drive, Orange, CA 92868, USA. ${ }^{2}$ Department of Anesthesiology, Johannes Gutenberg-University Medical Center, Langebeckstraße 1, 55131 Mainz, Germany. ${ }^{3}$ Department of Anesthesiology and Intensive Care Medicine, University Hospital Bonn, Sigmund Freu Straße 25, 53127 Bonn, Germany. ${ }^{4}$ Department of Anesthesiology and Intensive Care, Sheba Medical Center, Tel Aviv University, Ramat Gan 52621, Tel Aviv, Israel.

\section{Authors' contributions}

MC designed the study, collected and analyzed the data, drafted the manuscript, and gave final approval of the manuscript. GP designed the study, analyzed the data, drafted the manuscript, and gave final approval of the manuscript. CR collected the data and gave final approval of the manuscript. AH analyzed the data, drafted the manuscript, and gave final approval of the manuscript. AP designed the study, analyzed the data, drafted the manuscript and gave final approval of the manuscript. All authors read and approved the final version of the manuscript.

\section{Competing interests}

Maxime Cannesson is a consultant for Edwards Lifesciences (USA), Covidien (USA), Masimo Corp. (USA), ConMed (USA), Philips Medical System (Germany), CNsystem (Austria), BMeye (Netherlands), and Fresenius Kabi (Germany). Gunther Pestel is a consultant for BMeye (Netherlands) and Fresenius Kabi (Germany). Cameron Ricks has no conflict of interest to declare. Andreas Hoeft is a consultant for Edwards Lifesciences (USA). Azriel Perel is a consultant for BMeye (Netherlands), Pulsion (Germany), and Flowsense (Israel)

Received: 27 June 2011 Revised: 13 July 2011

Accepted: 15 August 2011 Published: 15 August 2011

\section{References}

1. Takala J: Surgery: risky business? Anesth Analg 2011, 112:745-746.

2. Moonesinghe SR, Mythen MG, Grocott MP: High-risk surgery: epidemiology and outcomes. Anesth Analg 2011, 112:891-901.

3. Pearse RM, Harrison DA, James P, Watson D, Hinds C, Rhodes A Grounds RM, Bennett ED: Identification and characterisation of the highrisk surgical population in the United Kingdom. Crit Care 2006, 10:R81.

4. Weiser TG, Regenbogen SE, Thompson KD, Haynes AB, Lipsitz SR, Berry WR, Gawande AA: An estimation of the global volume of surgery: a modelling strategy based on available data. Lancet 2008, 372:139-144.

5. Pearse R, Dawson D, Fawcett J, Rhodes A, Grounds RM, Bennet ED: Early goal-directed therapy after major surgery reduces complications and duration of hospital stay. A randomised, controlled trial [ISRCTN38797445]. Crit Care 2005, 9:R687-693.

6. Hamilton MA, Cecconi M, Rhodes A: A systematic review and metaanalysis on the use of preemptive hemodynamic intervention to improve postoperative outcomes in moderate and high-risk surgical patients. Anesth Analg 2011, 112:1392-402.

7. Gan TJ, Soppitt A, Maroof M, el-Moalem H, Robertson KM, Moretti E, Dwane P, Glass PS: Goal-directed intraoperative fluid administration reduces length of hospital stay after major surgery. Anesthesiology 2002, 97:820-826.

8. Rhodes A, Cecconi M, Hamilton M, Poloniecki J, Woods J, Boyd O, Bennett D, Grounds RM: Goal-directed therapy in high-risk surgical patients: a 15-year follow-up study. Intensive Care Med 2010, 36:1327-1332.

9. Boyd O, Bennett ED: Achieving the goal. Crit Care Med 1999, 27:2298-2299. 
10. Wiener RS, Welch HG: Trends in the use of the pulmonary artery catheter in the United States, 1993-2004. JAMA 2007, 298:423-429.

11. Rubenfeld GD, McNamara-Aslin E, Rubinson $\mathrm{L}$ : The pulmonary artery catheter, 1967-2007: rest in peace? JAMA 2007, 298:458-461.

12. Shoemaker WC, Appel PL, Kram HB, Waxman K, Lee TS: Prospective trial of supranormal values of survivors as therapeutic goals in high-risk surgical patients. Chest 1988, 94:1176-1186.

13. Boyd O, Grounds RM, Bennet ED: A randomized clinical trial of the effects of deliberate perioperative increase of oxygen delivery on mortality in high-risk surgical patients. JAMA 1993, 270:2699-2707.

14. Wakeling HG, MCFall MR, Jenkins CS, Woods WG, Miles WF, Barclay GR, Fleming SC: Intraoperative oesophageal Doppler guided fluid management shortens postoperative hospital stay after major bowel surgery. Br J Anaesth 2005, 95:634-642.

15. Leibowitz $A B$ : Is transpulmonary thermodilution cardiac output measurement an advance, or just another technique in search of an application? Crit Care Med 2009, 37:343-344

16. Brandstrup B, Tonnesen H, Beier-Holgersen R, Hjortso E, Ording H, LindorffLarsen K, Rasmussen MS, Lanng C, Wallin L, Iversen LH, Gramkow CS, Okholm M, Blemmer T, Svendsen PE, Rottensten HH, Thage B, Riis J, Jeppesen IS, Teilum D, Christensen AM, Graungaard B, Pott F: Effects of intravenous fluid restriction on postoperative complications: comparison of two perioperative fluid regimens: a randomized assessor-blinded multicenter trial. Ann Surg 2003, 238:641-648.

17. Brandstrup B: Fluid therapy for the surgical patient. Best Pract Res Clin Anaesthesiol 2006, 20:265-283

18. Perel A, Pizov R, Cotev S: Systolic blood pressure variation is a sensitive indicator of hypovolemia in ventilated dogs subjected to graded hemorrhage. Anesthesiology 1987, 67:498-502.

19. Michard F, Boussat S, Chemla D, Anguel N, Mercat A, Lecarpentier Y, Richard C, Pinsky MR, Teboul JL: Relation between respiratory changes in arterial pulse pressure and fluid responsiveness in septic patients with acute circulatory failure. Am J Respir Crit Care Med 2000, 162:134-138.

20. Cannesson M, Attof Y, Rosamel P, Desebbe O, Joseph P, Metton O, Bastien $\mathrm{O}$, Lehot JJ: Respiratory variations in pulse oximetry plethysmographic waveform amplitude to predict fluid responsiveness in the operating room. Anesthesiology 2007, 106:1105-1111.

21. Marik PE, Cavallazzi R, Vasu T, Hirani A: Dynamic changes in arterial waveform derived variables and fluid responsiveness in mechanically ventilated patients: a systematic review of the literature. Crit Care Med 2009, 37:2642-2647.

22. Buettner M, Schummer W, Huettemann E, Schenke S, van Hout N, Sakka SG: Influence of systolic-pressure-variation-guided intraoperative fluid management on organ function and oxygen transport. $\mathrm{Br} J$ Anaesth 2008, 101:194-199

23. Maguire S, Rinehart J, Vakharia S, Cannesson M: Respiratory variation in pulse pressure and plethysmographic waveforms: intraoperative applicability in a North American academic center. Anesth Analg 2010 112:94-96.

24. Brzezinski M, Luisetti T, London MJ: Radial artery cannulation: a comprehensive review of recent anatomic and physiologic investigations. Anesth Analg 2009, 109:1763-1781.

25. Rivers E, Nguyen B, Havstad S, Ressler J, Muzzin A, Knoblich B, Peterson E, Tomlanovich M: Early goal-directed therapy in the treatment of severe sepsis and septic shock. N Engl J Med 2001, 345:1368-1377.

26. Marik PE, Baram M, Vahid B: Does central venous pressure predict fluid responsiveness? A systematic review of the literature and the tale of seven mares. Chest 2008, 134:172-178.

27. Osman D, Ridel C, Ray P, Monnet X, Anguel N, Richard C, Teboul JL: Cardiac filling pressures are not appropriate to predict hemodynamic response to volume challenge. Crit Care Med 2007, 35:64-68

28. Gelman S: Venous function and central venous pressure: a physiologic story. Anesthesiology 2008, 108:735-748.

29. Parker MM: Goals for fluid resuscitation: a real challenge. Crit Care Med 2007, 35:295-296.

30. Mavis $B E$, Brocato JJ: Postal surveys versus electronic mail surveys. The tortoise and the hare revisited. Eval Health Prof 1998, 21:395-408.

31. Braithwaite D, Emery J, De Lusignan S, Sutton S: Using the Internet to conduct surveys of health professionals: a valid alternative? Fam Pract 2003, 20:545-551.
32. Haynes $A B$, Weiser TG, Berry WR, Lipsitz SR, Breizat AH, Dellinger EP, Herbosa T, Joseph S, Kibatala PL, Lapitan MC, Merry AF, Moorthy K, Reznick RK, Taylor B, Gawande AA: A surgical safety checklist to reduce morbidity and mortality in a global population. N Engl J Med 2009, 360:491-499.

33. Pronovost P, Needham D, Berenholtz S, Sinopoli D, Chu H, Cosgrove S, Sexton B, Hyzy R, Welsh R, Roth G, Bander J, Kepros J, Goeschel C: An intervention to decrease catheter-related bloodstream infections in the ICU. N Engl J Med 2006, 355:2725-2732.

doi:10.1186/cc10364

Cite this article as: Cannesson et al: Hemodynamic monitoring and management in patients undergoing high risk surgery: a survey among North American and European anesthesiologists. Critical Care 2011 15: R197.

\section{Submit your next manuscript to BioMed Central and take full advantage of:}

- Convenient online submission

- Thorough peer review

- No space constraints or color figure charges

- Immediate publication on acceptance

- Inclusion in PubMed, CAS, Scopus and Google Scholar

- Research which is freely available for redistribution 